\title{
Philosophiques
}

\section{Autour de la loi 50 Présentation}

\section{Robert Nadeau}

Volume 2, numéro 2, octobre 1975

URI : https://id.erudit.org/iderudit/203036ar

DOI : https://doi.org/10.7202/203036ar

Aller au sommaire du numéro

Éditeur(s)

Société de philosophie du Québec

\section{ISSN}

0316-2923 (imprimé)

1492-1391 (numérique)

Découvrir la revue

\section{Citer ce document}

Nadeau, R. (1975). Autour de la loi 50 : présentation. Philosophiques, 2(2),

341-342. https://doi.org/10.7202/203036ar d'utilisation que vous pouvez consulter en ligne.

https://apropos.erudit.org/fr/usagers/politique-dutilisation/ 


\section{INTERVENTIONS}

\section{AUTOUR DE LA LOI 50}

\section{Présentation}

L'Assemblée nationale du Québec a adopté, tout juste avant d'ajourner ses travaux pour l'été dernier, le texte final de la loi 50, texte qui inclut les amendements adoptés plus tôt en commission parlementaire. Le Québec se trouve ainsi doté, à l'instar de plusieurs provinces canadiennes et de nombreux pays, d'une Charte des Droits de l'Homme, officiellement appelée « Charte des droits et libertés de la personne ».

On sait que, sitôt votée en troisième lecture, cette loi a été immédiatement sanctionnée par le Lieutenant-gouverneur, de manière à ce que l'Assemblée nationale puisse nommer sur-lechamp les membres de la «Commission des droits de la personne », commission créée par cette nouvelle loi. Cette commission, chargée par la loi 50 de promouvoir l'application des principes contenus dans la Charte (notamment en recevant les plaintes et en enquêtrant sur les violations des droits et libertés consacrés par cette Charte), est présidée par Me René Hurtubise, qui a démissionné de son poste de direction à la Conférence des Recteurs et Principaux des Universités du Québec (C.R.E.P.U.Q.) en acceptant cette présidence. Le vice-président de la commission est Maurice Champagne, qui, pour sa part, a dû quitter la direction de la Ligue des Droits de l'Homme.

Le Gouvernement du Québec affirme que la Charte québécoise est $\ll$ la plus extensive des chartes de toutes les provinces canadiennes », et également «la plus efficace, par les pouvoirs que la loi confère à la nouvelle Commission des droits de la personne, ainsi que par les recours et les pénalités prévus en cas de violation des droits qui y sont énoncés» (texte d'un communiqué émis par le bureau du premier ministre). Il faut dire cependant que la charte québécoise ne fait pas partie des textes consti- 
tutionnels et n'a pas plus de portée légale qu'une autre loi ordinaire du parlement, comme c'est d'ailleurs le cas pour le «bill of right» adopté à Ottawa sous le Gouvernement Diefenbaker.

Il reste qu'il s'agit d'un texte énonçant solennellement des principes juridiques et des valeurs dites fondamentales, et qui a été doté par l'Assemblée nationale du Québec d'une certaine primauté sur les lois à venir, du moins en ce qui concerne certains chapitres de la loi 50. Vu l'importance de ce texte de loi, la Société de Philosophie du Québec a cru bon d'organiser un colloque sur les Droits de l'Homme dans le cadre du Quarantetroisième congrès de l'A.C.F.A.S. qui eut lieu à Moncton. Les trois textes qui suivent ont été présentés lors de ce colloque, le 7 mai 1975.

Robert Nadeau 